\title{
Synthesis, Characterization and Excellent Photocatalytic Performance of Iron-Carbon-Codoped Mesoporous Titania Nanocrystallines
}

\author{
Dongfang Zhang* and Liang GaO \\ College of Science, Huazhong Agricultural University, Wuhan 430070, PR China
}

(Received March 29, 2017; in final form October 26, 2017)

\begin{abstract}
Iron-carbon-codoped mesoporous titania nanocrystallines were synthesized by a modified sol-gel method based on the self-assembly technique using polyethylene glycol sorbitan monostearate (Tween 60) as template. The samples were characterized by X-ray diffraction, $\mathrm{N}_{2}$ adsorption, UV-vis diffuse reflectance spectroscopy, X-ray photoelectron spectroscopy, photoluminescence, electrochemical impedance spectroscopy, and transient photocurrent responses analysis. The photocatalytic activity of $\mathrm{Fe}-\mathrm{C}$-codoped $\mathrm{TiO}_{2}$ nanoparticles were evaluated by the degradation of methyl orange (MO), p-nitrophenol (PNP) and biphenol A (BPA) under visible light irradiation. It was found that the as-prepared Fe-C-codoped $\mathrm{TiO}_{2}$ sample showed excellent photocatalytic activity compared to undoped $\mathrm{TiO}_{2}$. The highest activity was obtained for Fe-C-codoped $\mathrm{TiO}_{2}$ sample calcined at $520^{\circ} \mathrm{C}$. The enhanced photocatalytic performances were attributed to the synergetic effects of good crystallizing action, appropriate phase composition and slow recombination rate of photogenerated charge carriers. Based on the experimental results, a reasonable photocatalytic mechanism of as-prepared Fe-C-codoped $\mathrm{TiO}_{2}$ photocatalysts was also proposed and discussed.
\end{abstract}

DOI: 10.12693/APhysPolA.133.1150

PACS/topics: titania, codoping, visible light, calcination temperature, photocatalytic mechanism

\section{Introduction}

Nowadays with industrialization and urbanization, the excessive emission of organic pollutants, heavy metal, and atmospheric pollutants has become an overwhelming problem all over the world. On this background, semiconductor-based photocatalysis technique provides a "green" method for completely decomposing harmful contaminants especially some azo dyes and endocrine disrupting compounds $[1,2]$. Among the plentiful semiconductor materials, semiconductor $\mathrm{TiO}_{2}$ has undoubtedly proven to be an excellent photocatalyst for the removal of aqueous pollutants. Nonetheless, due to its wide band gap $(3.20 \mathrm{eV})$ and fast recombination rate of photoinduced electron-hole pairs, $\mathrm{TiO}_{2}$ has a low efficiency for the utilization of solar energy, which limits its practical application. Therefore, the development of visible-lightdriven (VLD) photocatalysts has attracted great interest [3-10].

In recent years, huge amount of work is published currently on doped titanias as depollution photocatalysts. Meanwhile several strategies have been developed to shift the optical response of $\mathrm{TiO}_{2}$ from the UV to the visiblelight region for more efficient solar energy harvesting, the most prominent being metal/non-metal doping, metal deposition, surface sensitization, and coupling in composite semiconductors [11]. In non-metal doping, besides conventional doping by a single type of heteroatom species [12], co-doped $\mathrm{TiO}_{2}$ with two or more non-metals

*corresponding author; e-mail: billjcgao1@163.com has been confirmed to be an effective way for achieving higher visible-light photocatalytic activity. For example, N-C [13], N-B [14], S-N [15] and F-N [16] co-doped $\mathrm{TiO}_{2}$ were reported to significantly enhance the photocatalytic efficiency under visible light illumination. However, the surface area of nonmetal doped $\mathrm{TiO}_{2}$ will decrease with the increase of calcination temperature, which is not favorable to the catalytic efficiency of the photocatalysts. In order to further improve the photocatalytic activity, co-doped titania with combination of metal-nonmetal elements have been conducted. Some studies demonstrated that the co-doping with transition metal and nonmetal elements could effectively modify the electronic structures of $\mathrm{TiO}_{2}$ and shift its absorption edge to a low energy $[17,18]$. Therefore, it would be valuable to take a choice of co-doping with the two types of ions for getting the visible light-induced photocatalytic activity of titania. Besides, it becomes a challenge to find a facile, more cost-effective method for large-scale preparation of metal-nonmetal codoped mesoporous $\mathrm{TiO}_{2}$ materials.

Recently, the use of sol-gel method based on the selfassembly technique with nonionic surfactant has been reported as an effective approach to synthesize nonmetaldoped $\mathrm{TiO}_{2}$ [19-21]. Hydrocarbon surfactants can serve as pore directing agents to control the hydrolysis and condensation rates of the titanium precursor in the sol formulation, yielding tailor-designed $\mathrm{TiO}_{2}$ with high surface area, high porosity, small crystal size with narrow pore size distribution, and high photocatalytic activity under visible light irradiation. To the best of our knowledge, the synthesis of iron-carbon-co-doped $\mathrm{TiO}_{2}$ with a modified surfactant-assisted sol-gel method has not been reported yet in the literature. 
In this work, mesoporous Fe-C-co-doped titania photocatalyst was synthesized via a combination of a modified sol-gel process using hydrocarbon surfactants (Tween 60) as template or nonmetal doping precursor and calcination treatment technique. Herein $\mathrm{Fe}-\mathrm{C}$-codoping was used as an effective technique not only to extend the visible light response but also to achieve the optimum anatase/rutile mixed phase component in crystalline $\mathrm{TiO}_{2}$. All modern physical methods have been applied to perform the characterization of the prepared material. The synergy effect is claimed to be observed between iron and carbon dopants. The photocatalytic degradation of typical pollutants such as MO, PNP, and BPA were selected as probe reactions to evaluate the photocatalytic activities of $\mathrm{Fe}-\mathrm{C}$-codoped $\mathrm{TiO}_{2}$ sample under visible light irradiation. It was shown that the $\mathrm{Fe}-\mathrm{C}$-co-doping induces the red-shift of the absorption spectrum and reduces the electron-hole recombination, which results in the increase of the photocatalytic activity compared to pure titania. Based on above experimental results, a plausible mechanism was proposed to elucidate the facts.

\section{Experimental section \\ 2.1. Materials preparation}

All reagents used in this work were used as received without further purification. Millipore Co. MilliQ (MQ) water with resistivity of $18.0 \mathrm{M} \Omega \mathrm{cm}$ was used throughout the experiment. Titanium(IV) isopropoxide (TIP, $\left.M_{w}=284.2, \rho=0.954 \mathrm{~g} / \mathrm{cm}^{3}\right)$ and $\mathrm{Fe}\left(\mathrm{NO}_{3}\right)_{3} \cdot 9 \mathrm{H}_{2} \mathrm{O}$ $\left(M_{w}=404, \rho=1.68 \mathrm{~g} / \mathrm{cm}^{3}\right)$ were used as the precursors of $\mathrm{TiO}_{2}$, and iron, respectively. A nonionic surfactant Tween 60 (T60, polyethylene glycol sorbitan monostearate, Guoyao Chemical Co.) was employed as the pore directing agent and carbon precursor in the modified solgel solution. Fe-C- $\mathrm{TiO}_{2}$ nanoparticles were prepared by the self-assembly surfactant-based sol-gel method under mild conditions as follows. $10 \mathrm{ml} \mathrm{T60} \mathrm{was} \mathrm{dissolved} \mathrm{in}$ $40 \mathrm{ml}$ isopropyl alcohol (i-PrOH, 99.8\%, Guoyao Chemical Co.) and then $6 \mathrm{ml}$ titanium(IV) isopropoxide (TIP, $97 \%$, Sigma-Aldrich) and $0.40 \mathrm{~g} \mathrm{Fe}\left(\mathrm{NO}_{3}\right)_{3} \cdot 9 \mathrm{H}_{2} \mathrm{O}$ were added into the above solution under vigorous stirring. Finally, $7 \mathrm{ml}$ acetic acid (AcOH, Guoyao Chemical Co.) was added into the solution for the formation of water in the mixture. The sol-gel was aged at $70^{\circ} \mathrm{C}$ for $24 \mathrm{~h}$. To synthesize particles, the sol was dried at room temperature for $4 \mathrm{~h}$ and then calcined at 400,520 , and $600{ }^{\circ} \mathrm{C}$ for $3 \mathrm{~h}$. For comparison, the control sample was prepared though the same method, without adding the corresponding dopants and calcined at $400{ }^{\circ} \mathrm{C}$ for $3 \mathrm{~h}$. The catalysts produced are denoted as $\mathrm{TiO}_{2}, \mathrm{Fe}-\mathrm{C}-\mathrm{TiO}_{2}-400$, $\mathrm{Fe}-\mathrm{C}-\mathrm{TiO}_{2}-520$ and $\mathrm{Fe}-\mathrm{C}-\mathrm{TiO}_{2}-600$.

\subsection{Characterization}

The crystal structures of as-prepared samples were analyzed by the powder X-ray diffraction method (D/MAX$\mathrm{RB}$, Rigaku Corporation, Japan) with $\mathrm{Cu} K_{\alpha}$ radiation $(\lambda=0.154056 \mathrm{~nm})$. The Brunauer-EmmettTeller (BET) surface area, pore volume, porosity, BarretJoyner-Halenda (BJH) pore size and distribution (based on nitrogen adsorption and desorption isotherms) were determined by a Tristar 300 (Micromeritics) porosimeter analyzer. UV-vis absorption spectra were recorded using a UV-vis spectrophotometer (Shimadzu 2450PC) mounted with an integrating sphere accessory employing $\mathrm{BaSO}_{4}$ as white standard. A VG Multilab 2000 electron spectrometer (Thermo electron corporation, USA) with $\mathrm{Mg} K_{\alpha}$ source was used for X-ray photoelectron spectroscopy (XPS) measurement. Photoelectrochemical properties including electrochemical impedance spectroscopy (EIS) as well as transient photocurrent responses analysis were conducted by a standard threeelectrode configuration using an electrochemical workstation (CHI660E, Shanghai China). To gain the photoelectrochemical performance of as-prepared samples, the sample is dispersed into $0.5 \mathrm{wt} \%$ nafion solution to form a homogeneous suspension (the amount of powder catalyst is adjusted to be $3 \mathrm{mg} / \mathrm{ml}$ ) which is used as the precursor for the coating of film on the fluorine-doped tin oxide (FTO) glass surface by a spin coating method. Meanwhile, a platinum electrode and a saturated calomel electrode served as the counter and reference electrode, respectively. The working electrode was irradiated by incident light $(\lambda>400 \mathrm{~nm})$ through a UV-cutoff filter from a $300 \mathrm{~W}$ xenon arc lamp and $0.5 \mathrm{M} \mathrm{Na}_{2} \mathrm{SO}_{4}$ aqueous solution was employed as the electrolyte.

\subsection{Photocatalytic reaction}

The photoactivity of the catalyst is evaluated using the photocatalytic oxidation of aqueous methyl orange (MO) or p-nitrophenol (PNP) as the test reaction. A $300 \mathrm{~W}$ medium-pressure xenon arc lamp with a $400 \mathrm{~nm}$ cutoff filter were placed in front of the reaction vessel to obtain simulated solar light. For each experiment, $50 \mathrm{mg}$ of photocatalyst was added to $100 \mathrm{ml}$ of $10^{-5} \mathrm{~mol} / \mathrm{l} \mathrm{MO}$ solution stirred with a magnetic stirrer. Herein the used catalyst dosage is not more than $0.5 \mathrm{~g} / 1$ to make an optimization of the catalysts dose since scattering effects may responsible for reducing degradation extent at high dosage. The aerated suspension was first stirred in the dark for 60 min before illumination, which was sufficient to reach adsorption equilibrium. At the given time intervals, the sample of $5.0 \mathrm{ml}$ was taken from the mixture and immediately centrifuged at $10000 \mathrm{r} / \mathrm{min}$ for $5 \mathrm{~min}$, then filtered through a $0.22 \mathrm{~mm}$ Millipore filter. The concentration of aqueous MO was determined with a Hitachi UV-3010 spectrometer by measuring the maximum absorbance at $463 \mathrm{~nm}$. The remaining percentage of MO was determined by the formula: Removal $\%=\left(C_{0}-C\right) / C_{0} \times 100 \%$, where $C_{0}$ and $C$ represent the initial and residual concentrations of MO dye. Since PNP shows a major absorption band centered at $317 \mathrm{~nm}$, the progress of photocatalytic degradation was monitored through measuring the temporal spectral traces during the course of the photodegradation reaction. The chemical oxygen demand (COD) of biphenol A (BPA) or MO solution was measured by a representative chemistry method $\left(\mathrm{K}_{2} \mathrm{Cr}_{2} \mathrm{O}_{7}-\mathrm{Ag}_{2} \mathrm{SO}_{4}\right)$. The removal of COD (W) was calculated according to the following formula: $W \%=\left[C O D_{0}-C O D_{t}\right] / C O D_{0} \times 100 \%$, 
where $\mathrm{COD}_{0}$ and $\mathrm{COD}_{t}$ represent the $\mathrm{COD}$ of $\mathrm{BPA}$ or $\mathrm{MO}$ solution before and after illumination, respectively. All reported data were the average values of three parallel determinations.

\subsection{Hydroxyl radicals $(\bullet \mathrm{OH})$ determination}

The active species produced on the catalyst surface is measured by means of photoluminescence (PL) method using terephthalic acid as indicator, which involves the formation of hydroxyl radical $(\bullet \mathrm{OH})$. The $\bullet \mathrm{OH}$ radicals can react with terephthalic acid (TA) in basic solution to generate 2-hydroxyterephthalic acid, which emits a unique fluorescence signal with an emission peak at approximately $426 \mathrm{~nm}$.

\section{Results and discussion}

\subsection{Phase composition}

The photocatalytic activity of catalyst was greatly affected by its crystal structure and phase composition. Generally, $\mathrm{TiO}_{2}$ has three crystallite phases, whereas the anatase phase is reported with high photocatalytic activity than rutile or brookite phase with limited activity [22]. Therefore, phase composition of the as-prepared pure $\mathrm{TiO}_{2}$ and Fe-C-codoped $\mathrm{TiO}_{2}$, were analyzed by routine XRD technique. Figure 1 shows the effect of calcination temperature on the phase structures of as-prepared catalysts. For the reference $\mathrm{TiO}_{2}$ and the Fe-C-TiO -400 samples, the major crystalline phase detected was pure anatase according to the standard data (JCPDS card numbers 21-1272). By comparison, the annotated patterns of the Fe-C- $\mathrm{TiO}_{2}-520$ and $\mathrm{Fe}-\mathrm{C}-\mathrm{TiO}_{2}-600$ samples are similar since both of them contain the anatase/rutile mixed phases of $\mathrm{TiO}_{2}$, the main peak of the rutile phase being located at $2 \theta=27.32^{\circ}$ (110 plane) according to the known database (JCPDS no. 21-1276), while the remaining characteristic peaks located at $2 \theta=36.3^{\circ}, 41.4^{\circ}$, and $56.9^{\circ}$ can be ascribed to (101), (111), and (220) planes, respectively.

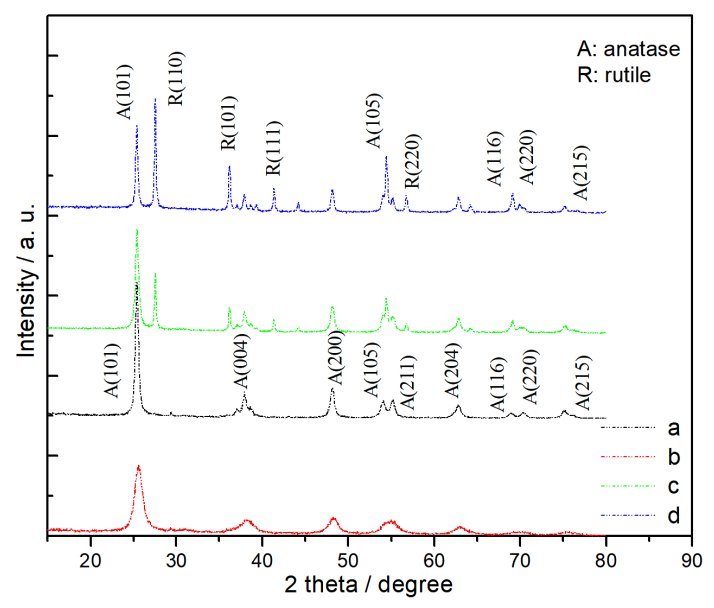

Fig. 1. XRD spectra of as-prepared catalysts obtained at different calcination temperature. (a) reference $\mathrm{TiO}_{2}$, (b) $\mathrm{Fe}-\mathrm{C}-\mathrm{TiO}_{2}-400$, (c) Fe-C- $\mathrm{TiO}_{2}-520$ and (d) Fe-C$\mathrm{TiO}_{2}-600$.
It can be found that the calcination temperature obviously influences the crystallization and phase composition of the $\mathrm{TiO}_{2}$ nanoparticles. At $400{ }^{\circ} \mathrm{C}$, only anatase $\mathrm{TiO}_{2}$ crystal phase could be identified in $\mathrm{Fe}-\mathrm{C}-\mathrm{TiO}_{2}$ and reference $\mathrm{TiO}_{2}$ samples and no other crystal phases could be resolved. The absence of reflections from the dopants can be attributed to their low concentration or these species were highly dispersed since X-ray powder diffraction is unable to detect lower percentages than $5 \%$ of an impurity or crystalline phase [23], and the incorporated amount of $\mathrm{Fe}$ is not more than $5 \mathrm{~mol} \% \mathrm{Fe}: \mathrm{Ti}$ in the current $\mathrm{Fe}-\mathrm{C}$-codoped $\mathrm{TiO}_{2}$ samples. In addition, the width of the (101) plane diffraction peak of anatase $\left(2 \Theta=25.3^{\circ}\right)$ becomes sharp as the calcination temperature increases and the corresponding peak intensities of anatase enhanced for the iron-carbon-codoped titania samples.

Nonetheless, the rutile phase appears when the calcination temperature reached to $520^{\circ} \mathrm{C}$, and a large number of rutile phase emerges when the calcination temperature was further elevated to $600{ }^{\circ} \mathrm{C}$. Since rutile is thermodynamically more stable than anatase at high temperatures, a certain amounts of rutile $\mathrm{TiO}_{2}$ is produced naturally as secondary products. Usually, the phase transformation for anatase to rutile occurred at about $550{ }^{\circ} \mathrm{C}$, whereas there already exists considerable rutile phase when calcination temperature was fixed at $520^{\circ} \mathrm{C}$. Therefore, it can be deduced that the presence of dopants favor the phase transformation from anatase to rutile during the thermal treatment in some degree. The mixture of anatase and rutile phases was found to significantly improve the photocatalytic activity of pure anatase in some catalytic applications [22].

For example, Degussa P-25, as a commercial photocatalyst consisting of an anatase-rutile proportion of $70 / 30$, is more active than pure anatase. It has been proposed that both the photocatalytic activity and the efficiency of mixed phase (rutile and anatase) $\mathrm{TiO}_{2}$ were enhanced due to synergic interactions between the two phases, which leads to spatial charge separation and hindered recombination [24]. The rutile and anatase contents in the as-prepared $\mathrm{Fe}-\mathrm{C}-\mathrm{TiO}_{2}$ samples can be estimated using the Spurr equation

$$
\begin{aligned}
& M_{R}=\frac{1}{1+0.8\left[I_{A}(101) / I_{R}(110)\right]} \times 100 \%, \\
& M_{A}=100-\frac{1}{1+0.8\left[I_{A}(101) / I_{R}(110)\right]} \times 100 \%,
\end{aligned}
$$

where $M_{R}$ and $M_{A}$ are, respectively, the mass fraction of rutile and anatase in the composite sample, $I_{R}$ and $I_{A}$ are the integrated intensities of the main peaks of rutile (110) and anatase (101), respectively. The phase content of the $\mathrm{Fe}-\mathrm{C}-\mathrm{TiO}_{2}-520$ is estimated to be $62.8 \%$ anatase and $37.2 \%$ rutile, whereas $\mathrm{Fe}-\mathrm{C}-\mathrm{TiO}_{2}-600$ sample contains $39.9 \%$ anatase and $60.1 \%$ rutile according to the above formula. The average grain size of Fe-C-codoped $\mathrm{TiO}_{2}$ or pure $\mathrm{TiO}_{2}$ sample was estimated from the Scherrer equation based on the anatase (101), rutile (110) main 
diffraction peaks along with the relative phase content. The results were 19.8, 28.7, and $37.6 \mathrm{~nm}$ for the asprepared Fe-C-TiO $2-400$, Fe-C-TiO $2-520$ and $\mathrm{Fe}-\mathrm{C}-\mathrm{TiO}_{2}-$ 600 samples (shown in Table $\mathrm{I}$ ), respectively, which is increased as the calcination temperature increases.

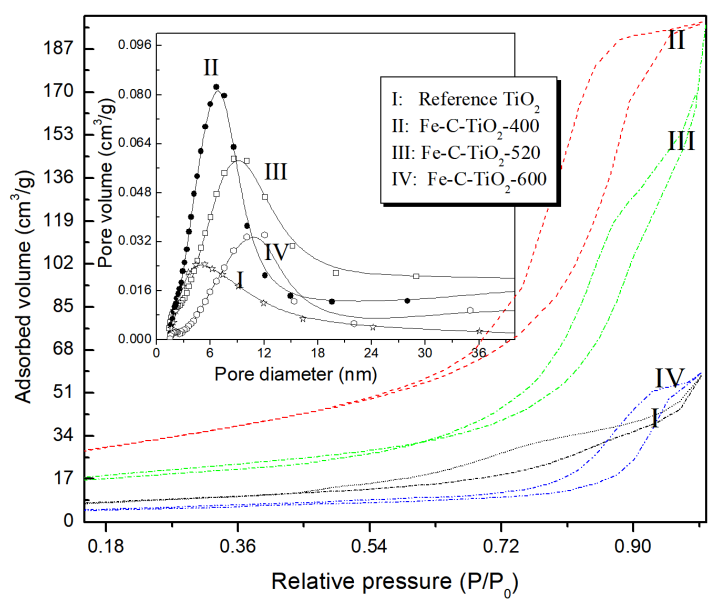

Fig. 2. $\mathrm{N}_{2}$ adsorption-desorption isotherms (a) and pore size distribution (b) of the as-prepared Fe-C- $\mathrm{TiO}_{2}$ samples calcined at different temperatures.

TABLE I

Crystalline size $a[\mathrm{~nm}]$, phase composition, $\mathrm{S}_{B E T}\left[\mathrm{~m}^{2} \mathrm{~g}^{-1}\right]$ values and average pore size $d[\mathrm{~nm}]$ of the $\mathrm{Fe}-\mathrm{C}-\mathrm{TiO}_{2}-n$ samples.

\begin{tabular}{c|c|c|c|c}
\hline \hline$n$ & Phase comp. & $S_{B E T}$ & $d$ & $a$ \\
\hline $\mathrm{TiO}_{2}$ (ref.) & anatase & 24.1 & 4.97 & 46.3 \\
400 & anatase & 98.5 & 6.54 & 19.8 \\
520 & $62.8 \% \mathrm{~A} / 37.2 \% \mathrm{R}$ & 67.0 & 8.90 & 28.7 \\
600 & $39.9 \mathrm{~A} / 60.1 \% \mathrm{R}$ & 28.6 & 10.92 & 37.6
\end{tabular}

As shown in Fig. 2, the BJH pore size distribution of as-prepared $\mathrm{Fe}-\mathrm{C}-\mathrm{TiO}_{2}-400$ catalyst was relative narrow implying good homogeneity of the pores and the pores were mainly in the range of $0-15 \mathrm{~nm}$ indicating the existence of mesoporous structures. With the calcination temperature increase, the BJH pore size distributions of the as-prepared $\mathrm{Fe}-\mathrm{C}-\mathrm{TiO}_{2}$ catalysts displayed in the inset of Fig. 2 exhibit a steady shift toward larger pores which can be attributed to the severe collapse of the initial porous structure occurring as the calcination temperature increases.

It has been already known that the surface area plays a necessary role in the photocatalytic activity of $\mathrm{TiO}_{2}$, and the adsorption is the prerequisite condition since any surface reaction in the adsorbed phase should have adsorption as the first step and dye molecule adsorption on the sample will be promoted due to notable effect of Fe-C-codoping in $\mathrm{TiO}_{2}$ catalyst. In the present case, $\mathrm{Fe}-\mathrm{C}-\mathrm{TiO}_{2}$ sample calcined at $400{ }^{\circ} \mathrm{C}$ gives a largest specific surface area among all the catalysts and the value is $98.5 \mathrm{~m}^{2} / \mathrm{g}$. However, the specific surface area starts to drop with increase of calcination temperature due to the growth of $\mathrm{TiO}_{2}$ crystallite. At $600{ }^{\circ} \mathrm{C}$, the specific surface area decreased to a value of $28.6 \mathrm{~m}^{2} / \mathrm{g}$. It can be simply found that all samples demonstrate a monotonic increase in the average pore size with increase of calcination temperature. These results indicate that the calcination temperature greatly affects the physical or structural properties of $\mathrm{TiO}_{2}$. Overall, the crystallite sizes of the samples after carbon and iron modification were smaller than that of reference $\mathrm{TiO}_{2}$. Since photocatalytic reactions are believed to take place on the illuminated surface, the smaller crystallite sizes or greater surface area will consequently help rapid mass transfer of the adsorbed molecules from bulk solution onto the catalyst surface, causing the photocatalytic process to be accelerated in a certain degree.

\subsection{Optical properties and XPS, PL characteristics}

Figure 3 shows the UV-vis absorption spectra of the reference $\mathrm{TiO}_{2}$ and various $\mathrm{Fe}-\mathrm{C}-\mathrm{TiO}_{2}$ samples. The typical onset of absorption near $387 \mathrm{~nm}$ can be assigned to the intrinsic band gap absorption of pure anatase $\mathrm{TiO}_{2}$ $\left(E_{g} \approx 3.2 \mathrm{eV}\right)$ and thus the absorption of reference $\mathrm{TiO}_{2}$ is limited only to the ultraviolet light region. The reference $\mathrm{TiO}_{2}$ shows intense absorptions in the UV range, but poor absorption in the visible range, whereas the absorption threshold values of the Fe-C-codoped $\mathrm{TiO}_{2}$ nanoparticles prepared by modified sol-gel method are extended up to the visible light region. It can be seen that there is a moderate shift in the onset absorption toward the longer wavelength for the $\mathrm{Fe}-\mathrm{C}-\mathrm{TiO}_{2}$ samples. The reason may be due to the new electronic state in the middle of the $\mathrm{TiO}_{2}$ band gap, charge-transfer transition between the $d$ electrons of the dopant and the CB of $\mathrm{TiO}_{2}$, the narrowed band gap resulted by C-doping, allowing visible light absorption [25].

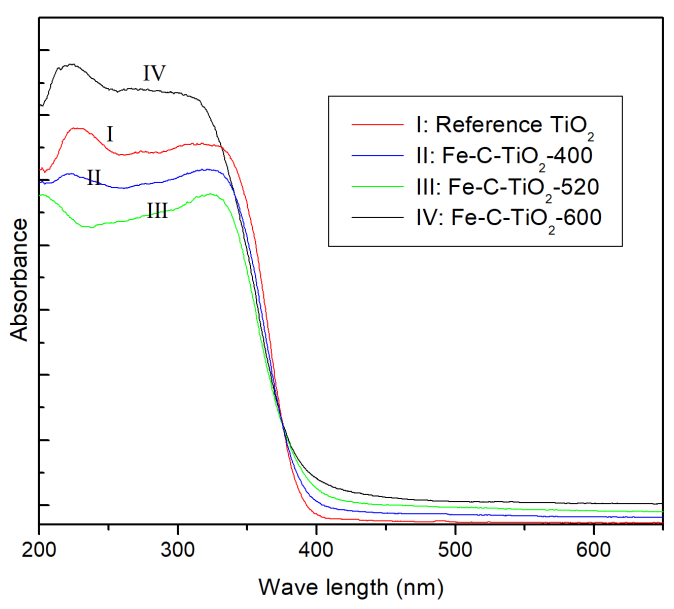

Fig. 3. UV-vis absorption spectra of reference $\mathrm{TiO}_{2}$ and $\mathrm{Fe}-\mathrm{C}-\mathrm{TiO}_{2}$ samples obtained with different calcination temperature.

It has been reported that non-metal elements could reduce the band gap energy of $\mathrm{TiO}_{2}$ by mixing their $p$ orbital of non-metal with O $2 p$ orbital via substitution of crystal lattice $\mathrm{O}$ or $\mathrm{Ti}$ to dopant species and the doping of 


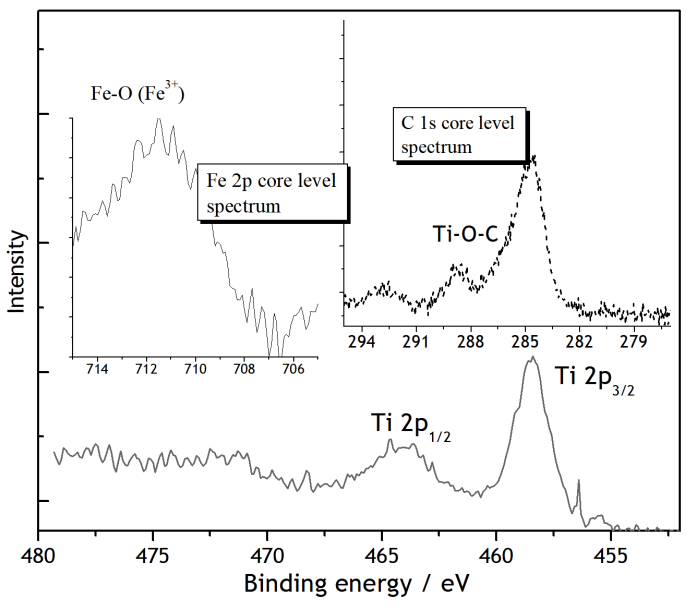

Fig. 4. High resolution Ti $2 p$ core level spectrum of the Fe-C-codoped $\mathrm{TiO}_{2}$ sample calcined at $520^{\circ} \mathrm{C}$ (inset: C 1s and Fe $2 p$ core level spectra).

various transitional metal ions into $\mathrm{TiO}_{2}$ could shift its optical absorption edge from UV to visible light range without a prominent change in $\mathrm{TiO}_{2}$ band gap. Moreover, the carbonaceous species as photosensitizer might result in the extended band tailing. It has been accepted that metal doping can introduce a new dopant energy level into the band gap of $\mathrm{TiO}_{2}$, close to and above the valence band [26, 27]. Therefore, the red shift of the absorption edge for the $\mathrm{Fe}-\mathrm{C}-\mathrm{TiO}_{2}$ samples can be ascribed to electronic transitions from the dopant level to the conduction band of $\mathrm{TiO}_{2}$ partly. From our results, the absorption intensity of $\mathrm{Fe}-\mathrm{C}-\mathrm{TiO}_{2}$ samples in the visible light region increased with the annealing temperature increase, which demonstrated that Fe-C-co-doping can effectively improve the absorption of visible light.

In the present case, co-doping facilitates the transformation from anatase to rutile phase to a certain extent, which is another reason for the red shift since the rutile phase has a band gap smaller than that of the anatase phase. The red shift in the visible range is of practical importance since an efficient utilization of visible light for photocatalytic degradation reactions will be possible. The enhanced ability to absorb visible light makes the asprepared $\mathrm{Fe}-\mathrm{C}-\mathrm{TiO}_{2}$ an effective photocatalyst for solar driven application.

The XPS investigation was conducted for representative $\mathrm{Fe}-\mathrm{C}-\mathrm{TiO}_{2}-520$ sample and the core level spectrum of $\mathrm{Ti} 2 p$ is given in Fig. 4. It can be found that two peaks ascribed to $\mathrm{Ti}^{4+} 2 p_{1 / 2}$ and $\mathrm{Ti}^{4+} 2 p_{3 / 2}$ are located at $464.1 \mathrm{eV}$ and $458.4 \mathrm{eV}$, respectively, which show slight shift to lower binding energy compared with those of pure $\mathrm{TiO}_{2}(464.3 \mathrm{eV}$ and $458.6 \mathrm{eV})$ [25]. This is probably attributed to the change of chemical environment after $\mathrm{C}$ doping. It is known that the binding energy of the element is influenced by its electron density. A decrease in binding energy implies an increase of the electron density. The electrons of $\mathrm{C}$ atoms may be partially transferred from $\mathrm{C}$ to $\mathrm{Ti}$ and $\mathrm{O}$, due to the higher electronegativ- ity of oxygen, leading to increased electron densities on both $\mathrm{Ti}$ and $\mathrm{O}$. The increase in electron density in the conduction band upon substitution of $\mathrm{Ti}^{4+}$ with $\mathrm{Fe}^{3+}$ brought about corresponding increase in the generation of surface state of $\mathrm{Ti}^{3+}$. The existence of the $\mathrm{Ti}^{3+}$ surface state would retard the recombination of the $\mathrm{h}^{+} / \mathrm{e}^{-}$ pairs to increase the lifetime of the charge carriers [28].

Besides, the high-resolution XPS spectrum of the C $1 \mathrm{~s}$ region was depicted in inset of Fig. 4 . It can be seen that C $1 s$ spectrum spans over a broad energy range from 277 to $290 \mathrm{eV}$, which can be well separated to two peaks. The first peak at $284.8 \mathrm{eV}$ can be assigned to adventitious hydrocarbon or carbon residues from the XPS instrument itself. The second peak at $288.8 \mathrm{eV}$ can be attributed to the appearance of $\mathrm{C}=\mathrm{O}$ bonds arising from the formation of carbonated species, whereas the underlying carbonaceous species incorporated could act as photosensitizer to induce the visible-light absorption and response. Normally, the $\mathrm{C}=\mathrm{O}$ band at $288.8 \mathrm{eV}$ has been considered as the formation of Ti-O-C bond due to the substitution of carbon for some of the lattice Ti atoms, though this peak may come from the surface functional group of carbon black. The peak at around $281.5 \mathrm{eV}$ reported as $\mathrm{Ti}-\mathrm{C}$ bond was not observed in the $\mathrm{Fe}-\mathrm{C}-\mathrm{TiO}_{2}$ sample, which suggests that carbon did not substitute for oxygen atom in the lattice of $\mathrm{TiO}_{2}$ in the current system. The Fe $2 p$ core leve spectrum was also shown in inset of Fig. 4, which demonstrates a main peak of $711.4 \mathrm{eV}$. It is reported that the binding energy in $\mathrm{Fe} 2 p_{3 / 2}$ region was located at 710.8 and $711.1 \mathrm{eV}$ in the formation of $\mathrm{Fe}_{3} \mathrm{O}_{4}$ and $\mathrm{Fe}_{2} \mathrm{O}_{3}$ [28]. Therefore it is proposed that Fe species did not exist as oxide but inserted interstitial position of $\mathrm{TiO}_{2}$ by coordinating to $\mathrm{O}$ atoms. This peak shows that $\mathrm{Fe}$ existed in the $3+$ oxidation state $\left(\mathrm{Fe}^{3+}\right)$. Lowlying $\mathrm{Fe}^{3+}$ level can be deemed responsible for the weak signals. The shift of electrons binding energy as compared to that in $\mathrm{Fe}_{2} \mathrm{O}_{3}$ (711.1 eV for $\left.\mathrm{Fe} 2 p_{3 / 2}\right)$ indicated the successful $\mathrm{Fe}^{3+}$ incorporation into the lattice of $\mathrm{TiO}_{2}$ nanoparticles to form $\mathrm{Fe}-\mathrm{O}-\mathrm{Ti}$ bonds in the sample [28].

The XPS results verify that $\mathrm{Fe}$ and $\mathrm{C}$ were successfully co-doped into the $\mathrm{TiO}_{2}$ lattice. The photoinduced charge separation rate is characterized by photoluminescence (PL) emission spectrum and it will help with discussion of results. If separation of electron-hole pairs has been enhanced relative to the pure counterparts, intensity of it should be lower than those of the other samples [29].

Figure 5 illustrates that the PL spectra of reference $\mathrm{TiO}_{2}$ and $\mathrm{Fe}-\mathrm{C}-\mathrm{TiO}_{2}$ samples calcined at 400, 500, and $600^{\circ} \mathrm{C}$ in the range of $350-600 \mathrm{~nm}$ under a $300 \mathrm{~nm}$ wavelength excitation source, respectively. As is displayed, reference $\mathrm{TiO}_{2}$ has the greatest intensity implying the rapid combination of electrons and holes, which means that electrons and holes in single-phase anatase $\mathrm{TiO}_{2}$ matrix are easy to recombine. For comparison, the asprepared Fe-C- $\mathrm{TiO}_{2}$ samples show slight decrease in $\mathrm{PL}$ intensity since doped species which act as electron trapping site can enhance the charge separation and suppress 


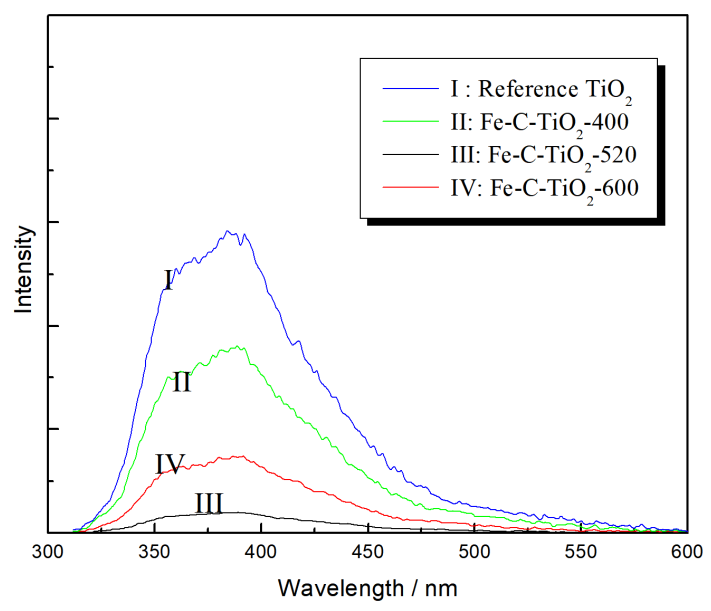

Fig. 5. The photoluminescence spectra for reference $\mathrm{TiO}_{2}$ and $\mathrm{Fe}-\mathrm{C}-\mathrm{TiO}_{2}$ samples calcined at different temperatures.

the recombination between electrons and holes. Moreover, $\mathrm{Fe}-\mathrm{C}-\mathrm{TiO}_{2}-520$ and $\mathrm{Fe}-\mathrm{C}-\mathrm{TiO}_{2}-600$ samples show efficient quenching of photoluminescence because of the formation of mixed anatase/rutile phases. The generated electrons will automatically drift from the conduction band of light-activated anatase to that of rutile from the thermodynamic consideration and thus the weakened intensity can reflect decrease in electron-hole recombination rate. In the present case, $\mathrm{Fe}-\mathrm{C}-\mathrm{TiO}_{2}-520$ sample with phase content of $62.8 \% \mathrm{~A} / 37.2 \% \mathrm{R}$ exhibits an optimum composition due to the lowest PL intensity and the lifetime of electron-hole pairs will be long lived. The more effective electron-hole separation of the Fe-Ccodoped $\mathrm{TiO}_{2}$ samples will be expected to improve the catalytic activity and benefit the photocatalytic degradation reaction. From this point of view, Fe-C-TiO ${ }_{2}-520$ sample will be expected to possess the best photocatalytic performance.

\subsection{Photoelectrochemical measurements}

The transient photocurrent responses of different electrodes can be recorded via several on-off cycles of irradiation and the results are shown in Fig. 6. As can be seen, reference $\mathrm{TiO}_{2}$ almost does not response to simulated visible light $(\lambda>400 \mathrm{~nm})$ because the wavelength employed is insufficient to activate the undoped $\mathrm{TiO}_{2}$ and the corresponding current intensity for $\mathrm{TiO}_{2}$ electrode is close to zero. For comparison, in each Fe-C-codoped $\mathrm{TiO}_{2}$ sample there exists an anodic photocurrent peak, which decays rapidly followed by a steady current, appears at the initial time of irradiation. When the light is interrupted, the holes accumulated in the surface state still continue to recombine, and a cathodic peak is observed. It is discernible that each sample was prompted in generating photocurrent with a reproducible response to on-off cycles, demonstrating the effective charge transfer and successful electron collection. In comparison with pure anatase $\mathrm{Fe}-\mathrm{C}-\mathrm{TiO}_{2}-400$ sample, mixed-phase Fe-Ccodoped $\mathrm{TiO}_{2}$ sample exhibited an increased photocur- rent density. The photocurrent density of the $\mathrm{Fe}-\mathrm{C}-\mathrm{TiO}_{2}$ $520 /$ FTO is greater than $0.045 \mathrm{~mA} \mathrm{~cm}^{-2}$, whereas that of $\mathrm{Fe}-\mathrm{C}-\mathrm{TiO}_{2}-600 /$ FTO and $\mathrm{Fe}-\mathrm{C}-\mathrm{TiO}_{2}-600 /$ FTO are 0.024 and $0.005 \mathrm{~mA} \mathrm{~cm}^{-2}$, respectively. The photocurrent of the $\mathrm{Fe}-\mathrm{C}-\mathrm{TiO}_{2}-520$ sample is about nine times as great as that of pure anatase $\mathrm{Fe}-\mathrm{C}-\mathrm{TiO}_{2}-400$ sample. The photocurrent improvement indicated a higher separation efficiency of photo-induced electron and holes, which partly attributes to the synthetic interaction between rutile and anatase phase in $\mathrm{Fe}-\mathrm{C}-\mathrm{TiO}_{2}-520$ and $\mathrm{Fe}-\mathrm{C}-\mathrm{TiO}_{2}-600$ samples. As a result, the recombination of photogenerated charge carriers was inhibited. According to the results of these photocurrent experiments, it was considered that the introduction of a mesoporous structure decreased the electron and hole recombination rate and the mesostructure of Fe-C-codoped $\mathrm{TiO}_{2}$ may be favorable for the interfacial separation of electron-hole pairs, which facilitate charge transport reflection over longer distances. Therefore, the mesostructure is beneficial for multiple reflections by incident light.

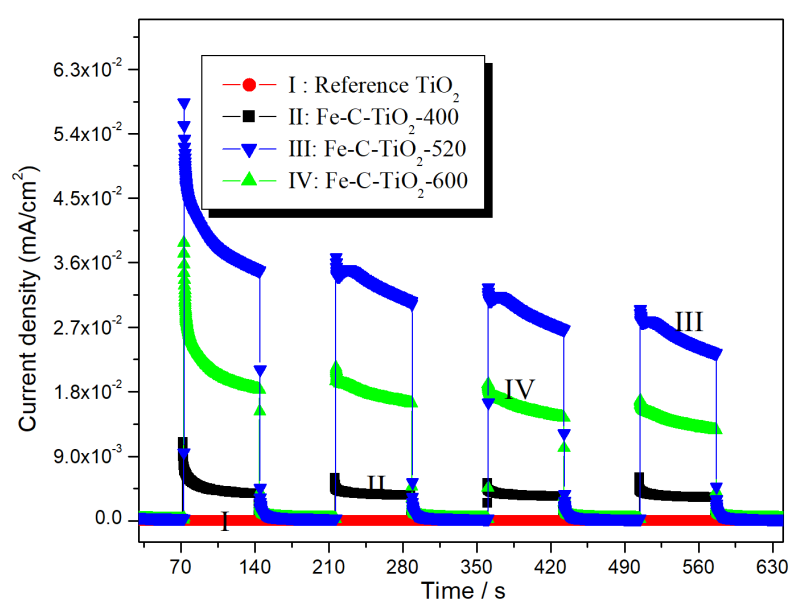

Fig. 6. Transient photocurrent response of the asprepared reference $\mathrm{TiO}_{2}$ and $\mathrm{Fe}-\mathrm{C}-\mathrm{TiO}_{2}$ samples under simulated visible light irradiation.

To provide additional evidence for the above mechanism, electrochemical impedance spectroscopy (EIS) were carried out under dark condition. The separation and transfer of electron and hole pairs was identified using EIS method [30]. The radius of the arc on the EIS Nyquist plot reflects the reaction rate occurring at the surface of electrode. The smaller the radius of the EIS Nyquist plot, the lower the electric charge-transfer resistance is.

It can be seen from Fig. 7 that the arc radii of the samples are arranged similar to the trend of the photocurrent. Fe-C- $\mathrm{TiO}_{2}-520$ shows the smallest arc radius, which further confirms that the $\mathrm{Fe}-\mathrm{C}-\mathrm{TiO}_{2}-520$ electrode has a higher separation efficiency of photo-generated electronhole pairs and faster charge-transfer than the other samples at the solid-liquid interface. Therefore, the results confirm that the Fe-C-co-doped $\mathrm{TiO}_{2}$ samples, especially $\mathrm{Fe}-\mathrm{C}-\mathrm{TiO}_{2}-520$, can effectively inhibit the recombination 


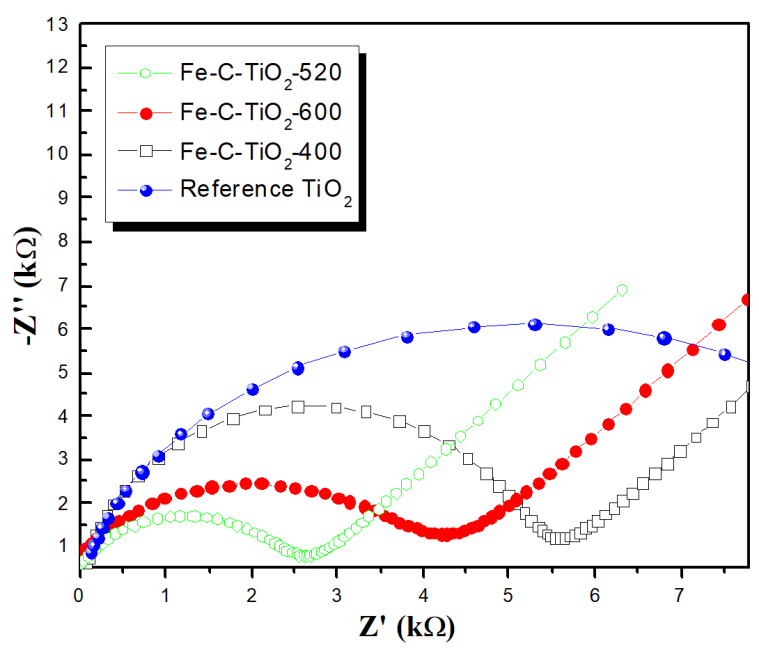

Fig. 7. Nyquist impedance plots of the as-prepared reference $\mathrm{TiO}_{2}$ and $\mathrm{Fe}-\mathrm{C}-\mathrm{TiO}_{2}$ samples in $0.5 \mathrm{M} \mathrm{Na}_{2} \mathrm{SO}_{4}$ aqueous solution.

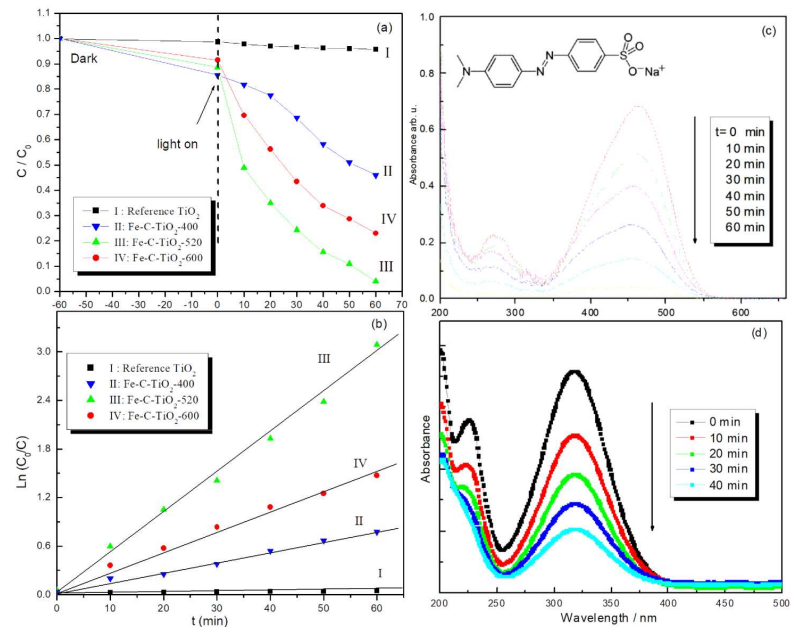

Fig. 8. The degradation conversions of MO (a) using different catalysts under simulated visible light irradiation $(\lambda>400 \mathrm{~nm})$, (b) plots of $\ln \left(C_{0} / C\right)$ of $\mathrm{MO}$ as well as linear fit against reaction time and $(\mathrm{c}, \mathrm{d})$ temporal spectral traces during the course of the photodegradation of MO and PNP with Fe-C- $\mathrm{TiO}_{2}-520$ sample.

of photo-induced electron-hole pairs, which in turn leads to the high photocurrent response and improved activity in photocatalytic reaction.

\subsection{Evaluation of photocatalytic activity}

Photolysis tests were carried out as a control experiment including the dark adsorption results. The photocatalytic performances of as-prepared catalysts toward the decomposition of MO under simulated visible light irradiation were shown in Fig. 8. Before the light switch on, the $\mathrm{MO}$ adsorption ability of $\mathrm{TiO}_{2}$ catalysts was moderately improved after Fe-C-co-doping, which is probably due to the larger $S_{B E T}$. Control experiment results implied that the MO degradation performance can be ignored in the absence of either irradiation or photocatalyst, indicating that MO was degraded via photocatalytic

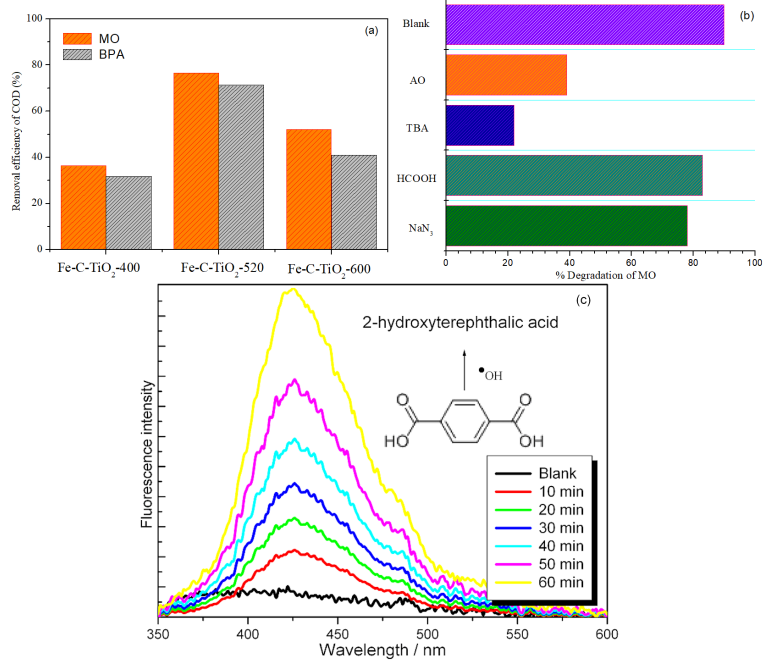

Fig. 9. COD removal of MO and BPA photolyzed over as-prepared Fe-C-codoped $\mathrm{TiO}_{2}$ samples under simulated visible light irradiation $(\lambda>400 \mathrm{~nm})$ for $1.0 \mathrm{~h}$ (a), trapping experiment of active species during the photocatalytic degradation of $\mathrm{MO}$ using $\mathrm{Fe}-\mathrm{C}-\mathrm{TiO}_{2}-520$ catalyst (b) and change of fluorescence spectrum with addition of $\mathrm{Fe}-\mathrm{C}-\mathrm{TiO}_{2}-520$ catalyst in $3.0 \times 10^{-4} \mathrm{M}$ basic solution of terephthalic acid (c).

process. Thus the result indicates self-photodegradation of MO or dye-photosensitized reaction is almost negligible in the current situation. Also adsorption of the organic substrate is not a crucial process. Generation of reactive oxygen species, usually responsible for the pollutant degradation, does not require adsorption of the organic molecule, and this issue will be discussed later.

The photocatalytic efficiency of MO over the above samples for such kind of experiments was shown in Fig. 8a. It can be seen that the Fe-C-TiO ${ }_{2}-520$ and Fe$\mathrm{C}-\mathrm{TiO}_{2}-600$ catalysts display high photocatalytic activity, as almost $96 \%$ and $77 \%$ of $\mathrm{MO}$ was degraded for only $60 \mathrm{~min}$, respectively. That is, during $60 \mathrm{~min}$ photocatalysis the $\mathrm{Fe}-\mathrm{C}-\mathrm{TiO}_{2}-520$ sample was able to completely bleach MO dye and the color of MO solution remained obvious after the adsorption process of MO by catalyst while it disappeared absolutely after the photocatalytic reaction. By comparison, $\mathrm{Fe}-\mathrm{C}-\mathrm{TiO}_{2}-400$ and reference $\mathrm{TiO}_{2}$ only resulted in a partial and negligible decomposition, respectively. The kinetic behaviors of photocatalytic decomposition of MO treated with asprepared samples under simulated light source were explored by using the Langmuir-Hinshelwood model, given as: $\ln \left(C_{0} / C\right)=k t$, where $C$ is the dye concentration at fixed time $t, C_{0}$ is the initial concentration of the dye solution, and $k$ is the pseudo-first order rate constant.

The linear plot between $\ln \left(C_{0} / C\right)$ and time $t$ of light exposure for all the used catalysts are shown in Fig. 8b. The reaction rate of the $\mathrm{MO}$ decomposition over Fe-C$\mathrm{TiO}_{2}-520$ sample is estimated to be about $0.052 \mathrm{~min}^{-1}$, which is about two and four folds higher than that of Fe-C-TiO $-600\left(k=0.024 \mathrm{~min}^{-1}\right)$ and $\mathrm{Fe}-\mathrm{C}-\mathrm{TiO}_{2}-400$ 
$\left(k=0.012 \mathrm{~min}^{-1}\right)$, respectively. The reaction rate of Fe-C-TiO -520 sample is far beyond than that of reference $\mathrm{TiO}_{2}\left(k=0.0007 \mathrm{~min}^{-1}\right)$ based on kinetic theories for catalytic reactions. For the $\mathrm{Fe}-\mathrm{C}-\mathrm{TiO}_{2}$ sample, the sample calcined at $520^{\circ} \mathrm{C}$ shows the highest photocalytic activity, which reached to the $96 \%$ after the irradiation for $60 \mathrm{~min}$. With the calcination temperature increase to $600^{\circ} \mathrm{C}$, the degradation rate of methyl orange decreased. For $\mathrm{TiO}_{2}$ catalysts, the activities were further improved by Fe-C-co-doping. This is probably due to the synergistic effect of co-doping which improved the $S_{B E T}$, enhanced absorption of visible light, and inhibited the recombination of photoinduced electron-hole pairs.

The excellent photocatalytic performance for the FeC-co-doped $\mathrm{TiO}_{2}$ samples especially for Fe-C- $\mathrm{TiO}_{2}-520$ sample can be attributed to the following factors. One is that $\mathrm{Fe}-\mathrm{C}-\mathrm{TiO}_{2}$ calcined at $520^{\circ} \mathrm{C}$ has a mesoporous and mixed-phase structure, which favors interfacial charge transfer and catalytic reaction, but further increased calcination temperature will lead to the sintering and growth of $\mathrm{TiO}_{2}$ crystallites resulting in the significant decrease of surface area of the $\mathrm{Fe}-\mathrm{C}-\mathrm{TiO}_{2}$ sample. Another is that the $\mathrm{Fe}-\mathrm{C}-\mathrm{TiO}_{2}-520$ sample has a lowest PL intensity or a highest photocurrent response due to a decrease in the recombination rate of photogenerated electronholes and effective charge separation under light irradiation. These causes may result in the superior photocatalytic activity for $\mathrm{Fe}-\mathrm{C}-\mathrm{TiO}_{2}-520$ sample.

Furthermore, changes in the absorbance profiles of $\mathrm{MO}$ solution in the presence of $\mathrm{Fe}-\mathrm{C}-\mathrm{TiO}_{2}-520$ sample under simulated visible-light irradiation are shown in Fig. 8c. Two characteristic peaks (273 nm, $463 \mathrm{~nm}$ ) are observed, and maximum absorption occurs at $463 \mathrm{~nm}$. With the irradiation time increase, the peaks at $273 \mathrm{~nm}$ and $463 \mathrm{~nm}$ reduced quickly. The band at $273 \mathrm{~nm}$ and $463 \mathrm{~nm}$ became very weak in $60 \mathrm{~min}$, suggesting almost complete photodegradation of MO.

In order to exclude the dye sensitization under visible light, degradation of typical colorless organic contaminant is a good choice. In this regard, aqueous PNP was selected as a model pollutant to estimate the photocatalytic performance in our study. The photodegradation process of PNP under visible light irradiation over Fe-C$\mathrm{TiO}_{2}-520$ catalyst is given in Fig. 8d, which illustrates temporal evolution of the spectral changes during photodecomposition of PNP. It displays that the main peak intensity of PNP at $317 \mathrm{~nm}$ decreased obviously with increase of irradiation time, suggesting that PNP can be effectively decomposed over $\mathrm{Fe}-\mathrm{C}-\mathrm{TiO}_{2}-520$ catalyst under visible light. Because colorless PNP cannot sensitize photocatalyst, this can be used a forceful proof to confirm the photocatalytic activity of the representative Fe-C-codoped $\mathrm{TiO}_{2}\left(\mathrm{Fe}-\mathrm{C}-\mathrm{TiO}_{2}-520\right)$ catalyst.

Additional test such as COD analysis was applied for approved mineralization of degradation products. An appropriate substrate can be used for the evaluation of photocatalytic reaction, which usually refers to a colorless pollutant such as BPA. In order to further evaluate the photocatalytic performance, the removal of COD for MO and BPA after $1.0 \mathrm{~h}$ irradiation was investigated and is shown in Fig. 9a. It was found that the COD removal efficiency was $32.0 \div 77.0 \%$ after $60 \mathrm{~min}$. It is easy to found that the COD removal efficiency for MO removal was lower than the corresponding degradation efficiency (by ca. 20\%) within the studied reaction period. These results further indicated that MO dye was oxidized via a number of intermediates prior to its final product of $\mathrm{CO}_{2}$. As is displayed, it is clear that the removal efficiency of COD for BPA or MO was increased in the presence of these catalysts with the order following $\mathrm{Fe}-\mathrm{C}-\mathrm{TiO}_{2}$ $520>\mathrm{Fe}-\mathrm{C}-\mathrm{TiO}_{2}-600>\mathrm{Fe}-\mathrm{C}-\mathrm{TiO}_{2}-400$. The efficiency of COD removal was strongly affected by the structure and physical properties of Fe-C-co-doped $\mathrm{TiO}_{2}$ samples, whereas the COD removal rates were similar to degradation of BPA or MO by Fe-C- $\mathrm{TiO}_{2}-520$ alone. The result confirms the superior photocatalytic properties of Fe-C$\mathrm{TiO}_{2}-520$ than other Fe-C-co-doped $\mathrm{TiO}_{2}$ samples, and $\mathrm{BPA}$ or MO can be effectively decomposed to smaller organic molecules such as carbonate, $\mathrm{CO}_{2}$ and other harmless or less harmful inorganics at last.

\subsection{Photocatalytic mechanism}

It is already accepted that lots of reactive oxygen species (ROSs) including $\mathrm{h}^{+}, \bullet \mathrm{OH}$ and $\bullet \mathrm{O}_{2}$ perhaps involved in photocatalytic oxidation process [31,32]. Three factors, namely surface area of the photocatalyst, light absorption capability, and charge separation or transfer are of paramount importance for the efficient degradation reaction. High surface area in codoped $\mathrm{TiO}_{2}$ can be effective in increasing the absorption of the reactants on the active sites as compared to reference $\mathrm{TiO}_{2}$. However, Fe-C- $\mathrm{TiO}_{2}-400$ exhibits the highest surface area but the activity is lower than the $\mathrm{Fe}-\mathrm{C}-\mathrm{TiO}_{2}-520$ suggesting that the surface area is not the major reason for the enhancement. Radiative recombination of photogenerated charges is the most important factor that is responsible for the observed advanced catalytic activity. In this regard, increase charge separation is also held liable for the higher activity for the codoped $\mathrm{TiO}_{2}$. Compared with reference $\mathrm{TiO}_{2}$, there is reduction in emission intensity for Fe-C-codoped $\mathrm{TiO}_{2}$ and intensity is further decreased for $\mathrm{Fe}-\mathrm{C}-\mathrm{TiO}_{2}-520$. This shows that upon codoping the radiative recombinations of charge carrier is considered to be decreased due to their trapping in the dopant sites or effective charge transfer take place from interface between anatase and rutile. Therefore, radical and hole trapping experiments were undertaken to verify the existence of oxidative species and to reveal the internal mechanism. The experimental procedure is similar to photocatalysis reaction. In brief, $0.60 \mathrm{mM}$ tert-butanol (TBA, a quencher of $\bullet \mathrm{OH})$, sodium azide $\left(\mathrm{NaN}_{3}\right.$, a quencher of $\left.{ }^{1} \mathrm{O}_{2}\right)$, ammonium oxalate $\left(\mathrm{AO}\right.$, a quencher of $\left.\mathrm{h}^{+}\right)$, and formic acid $\left(\mathrm{HCOOH}\right.$, a quencher of $\bullet \mathrm{O}_{2}^{-}$) were added to MO solution. As shown in Fig. 9b, compared to without any scavenger on this occasion, the photocatalytic activity in $\mathrm{Fe}-\mathrm{C}-\mathrm{TiO}_{2}-520$ catalytic system is greatly suppressed by the addition of TBA $(\bullet \mathrm{OH}$ radical scavenger $)$ 
and $\mathrm{AO}$ (hole scavenger), indicate the main roles of $\bullet \mathrm{OH}$ and $\mathrm{h}^{+}$for $\mathrm{MO}$ degradation. The addition of $\mathrm{HCOOH}$ which acting as a sacrificial electron donor $\left(\bullet \mathrm{O}_{2}^{-}\right.$radical scavenger $)$ and $\mathrm{NaN}_{3}\left({ }^{1} \mathrm{O}_{2}\right.$ scavenger $)$ exerted only a feeble influence in $\mathrm{PCO}$ process of $\mathrm{MO}$, suggesting that - $\mathrm{O}_{2}^{-}$and ${ }^{1} \mathrm{O}_{2}$ played comparatively minor role for $\mathrm{MO}$ degradation. It is clear that the degradation of $\mathrm{MO}$ was restrained in the presence of these scavengers with the order of significance following $\mathrm{TBA}>\mathrm{AO}>\mathrm{HCOOH}$ $>\mathrm{NaN}_{3}$. Thus, it is postulated that $\bullet \mathrm{OH}$ followed by $\mathrm{h}^{+}$ significantly contributed to the degradation of MO, while the roles of $\bullet \mathrm{O}_{2}^{-}$and ${ }^{1} \mathrm{O}_{2}$ was less significant. On the basis of the experimental observations, a tentative mechanism for photocatalytic degradation of dye may be proposed as below. Dissolved oxygen reacts with the electron located in the conduction band of semiconductor forming oxygen radical anion. This radical anion reacts with proton forming hydrogen peroxide radical, which in turn will oxidize the dye to its leuco form. This leuco form ultimately degrades to the products. Also $\bullet \mathrm{O}_{2}^{-}$radicals formed in-situ during the reaction, leading to termination of the chain reaction to successfully produce hydroxyl radicals. Thus it was confirmed that $\bullet \mathrm{OH}$ radical does act as main oxidizing species, as the reaction rate greatly affected in the present of $\bullet \mathrm{OH}$ radical scavenger, TBA.

In order to further detecting hydroxyl radicals by employing terephthalic acid as a probe molecule, photoluminescence (PL) data should be provided since $\bullet \mathrm{OH}$ was speculated as the predominant active species that participate in the reaction. The $\bullet \mathrm{OH}$ radicals can react with terephthalic acid (TA) in basic solution to generate 2hydroxyterephthalic acid, which emits a unique fluorescence signal with an emission peak at approximately 426 $\mathrm{nm}$. The fluorescence intensity is directly proportional to the amount of $\bullet \mathrm{OH}$ radicals formed in water. It can be seen from Fig. 9c that $\mathrm{Fe}-\mathrm{C}-\mathrm{TiO}_{2}-520$ catalytic system can produce $\bullet \mathrm{OH}$ after illumination and the fluorescence intensity of PL signal at $426 \mathrm{~nm}$ increases along with irradiation time. This suggests that the fluorescence is caused by chemical reactions of TA with $\bullet \mathrm{OH}$ formed in $\mathrm{Fe}-\mathrm{C}-\mathrm{TiO}_{2}-520$ catalytic system, while the fluorescence intensity was proportional to the amount of $\bullet \mathrm{OH}$ produced. Hence, $\bullet \mathrm{OH}$ is the reactive oxygen species to get rid of MO straightforward.

\section{Conclusions}

We have synthesized the iron and carbon-codoped mesoporous $\mathrm{TiO}_{2}$ nanocrystallines as novel catalysts by a modified sol-gel method based on the self-assembly technique using polyethylene glycol sorbitan monostearate (Tween 60) as template. The presence of carbon and iron species have been inferred to play a key role in extending the photoactivity to visible light region, effectively narrowing the band gap, and inhibiting the recombination of excitions. The high photoactivity of the $\mathrm{Fe}-\mathrm{C}-\mathrm{TiO}_{2}$ can be attributed to the large surface area, the red shift in adsorption edge, and low recombination probability of electron/hole pairs. The results presented in this work demonstrate that simultaneous carbon and iron doping is an ideal route for the development of effective photocatalyst performing under visible light illumination. The mesoporous Fe-C-codoped $\mathrm{TiO}_{2}$ is a promising photocatalytic material which has good potential for environmental remediation.

\section{References}

[1] Y.D. Guo, G.K. Zhang, H.H. Gan, Y.L. Zhang, Dalton Trans. 41, 12697 (2012).

[2] J. Li, Y. Yu, L.Z. Zhang, Nanoscale 6, 8473 (2014).

[3] J.L Zhang, Y.M Wu, M.Y Xing, S.A.K. Leghari, S. Sajjad, Energy Environm. Sci. 3, 715 (2010).

[4] G.H. Dong, L.Z. Zhang, J. Mater. Chem. 22, 1160 (2012).

[5] J. Li, L.J. Cai, J. Shang, Y. Yu, L.Z. Zhang, Adv. Mater. 28, 4059 (2016).

[6] G.H. Dong, Z.H. Ai, L.Z. Zhang, RSC Adv. 4, 5553 (2014).

[7] H. Li, L.Z. Zhang, Nanoscale 6, 7805 (2014).

[8] H. Li, J.G. Shi, K. Zhao, L.Z. Zhang, Nanoscale 6, 14168 (2014).

[9] H. Li, J. Shang, J.G. Shi, K. Zhao, L.Z. Zhang, Nanoscale 8, 1986 (2016).

[10] J. Li, L.Z. Zhang, Y.J. Li, Y. Yu, Nanoscale 6, 167 (2014).

[11] S. Girish Kumar, K.S.R. Koteswara Rao, Appl. Surf. Sci. 391, 124 (2017).

[12] Y.D. Guo, G.K. Zhang, J. Liu, Y.L. Zhang, $R S C A d v$. 3, 2963 (2013).

[13] D.Y. Li, Y.G. Zhang, Y.L. Zhang, X.F. Zhou, S.J. Guo, J. Hazard. Mater. 258-259, 43 (2013).

[14] Y.L. Zhang, D.J. Wang, G.K. Zhang, Chem. Eng. J. 173, 1 (2011).

[15] Y.L. Zhang, H.H. Gan, G.K. Zhang, Chem. Eng. J. 172, 936 (2011).

[16] Y.L. Zhang, L.J. Deng, G.K. Zhang, H.H. Gan, Colloid Surf. A-Physicochem. Eng. Asp. 384, 137 (2011).

[17] Y.L. Zhang, Y.D. Guo, G.K. Zhang, Y.Y. Gao, Appl. Clay. Sci. 51, 335 (2011).

[18] M. Nasir, J.Y. Lei, W. Iqbal, J.L. Zhang, Appl. Surf. Sci. 364, 446 (2016).

[19] Z. Wan, G.K. Zhang, J.T. Wang, Y.L. Zhang, RSC Adv. 3, 19617 (2013).

[20] Y.L. Zhang, D.Y. Li, Y.G. Zhang, X.F. Zhou, S.J. Guo, L.B. Yang, J. Mater. Chem. A 2, 8273 (2014).

[21] G.K. Zhang, Y.Y. Gao, Y.L. Zhang, Y.D. Guo, Environ. Sci. Technol. 44, 6384 (2010).

[22] K. Zhao, L.Z. Zhang, J.J. Wang, Q.X. Li, W.W. He, J.J. Yin, J. Am. Chem. Soc. 135, 15750 (2013).

[23] H. Li, J. Shang, Z.H. Ai, L.Z. Zhang, J. Am. Chem. Soc. 137, 6393 (2015).

[24] M. Nasir, Z.H. Xi, M.Y. Xing, J.L. Zhang, F. Chen, B.Z. Tian, S. Bagwasi, J. Phys. Chem. C. 117, 9520 (2013). 
[25] G.H. Dong, L.Z. Zhang, J. Phys. Chem. C. 117, 4062 (2013).

[26] D.Y. Qi, M.Y. Xing, J.L. Zhang, J. Phys. Chem. C 118, 7329 (2014).

[27] H. Li, J. Shang, H.J. Zhu, Z.P. Yang, Z.H. Ai, L.Z. Zhang, ACS Catal 6, 8276 (2016).

[28] Y.J. Gu, M.Y. Xing, J.L. Zhang, Appl. Surf. Sci. 319, 8 (2014).
[29] S. Sajjad, S.A. Leghari, F. Chen, J.L. Zhang, Chem. Eur. J. 16, 13795 (2010)

[30] J. Li, G.M. Zhan, Y. Yu, L.Z. Zhang, Nat. Commun. 7, 11480 (2016).

[31] J. Jiang, X. Zhang, P.B. Sun, L.Z. Zhang, J. Phys. Chem. C 115, 20555 (2011).

[32] X. Zhang, L.Z. Zhang, T.F. Xie, D.J. Wang, J. Phys. Chem. C 113, 7371 (2009). 